\title{
Randomised controlled trial of postnatal sodium supplementation on body composition in 25 to 30 week gestational age infants
}

\author{
Gary Hartnoll, Pierre Bétrémieux, Neena Modi
}

\begin{abstract}
Aims-To compare the effects of early and delayed sodium supplementation on body composition and body water compartments during the first two weeks of postnatal life.

Methods-Preterm infants of 25-30 weeks' gestation were stratified and randomly assigned according to gender and gestational age, to receive a sodium intake of $4 \mathrm{mmol} / \mathrm{kg} / \mathrm{day}$ beginning either on the second day after birth or when weight loss of $6 \%$ of birthweight had been achieved. Daily sodium intake, total fluid intake, energy intake, urine volume, and urinary sodium excretion were recorded. Total body water was measured by $\mathrm{H}_{2}{ }^{18} \mathrm{O}$ dilution on days 1, 7, and 14, and extracellular fluid volume by sodium bromide dilution on days 1 and 14.
\end{abstract}

Results-Twenty four infants received early, and 22 delayed, sodium supplementation. There were no significant differences between the groups in body water compartments on day 1 . In the delayed group, but not the early group, there was a significant loss of total body water during the first week (delayed $-44 \mathrm{ml} / \mathrm{kg}, \mathrm{p}=0.048$; early $6 \mathrm{ml} / \mathrm{kg}, p=0.970)$. By day 14 the delayed, but not the early group, also had a significant reduction in extracellular fluid volume (delayed $-53 \mathrm{ml} / \mathrm{kg}, \mathrm{p}=0.01$; early $-37 \mathrm{ml} / \mathrm{kg}, \mathrm{p}=0.2$ ). These changes resulted in a significant alteration in body composition at the end of the first week (total body weight: delayed $791 \mathrm{ml} / \mathrm{kg}$; early 849 $\mathrm{ml} / \mathrm{kg}, \mathrm{p}=0.013)$. By day 14 there were once again no significant differences in body composition between the two groups.

Conclusions-Body composition after preterm birth is influenced by the timing of introduction of routine sodium supplements. Early sodium supplementation can delay the physiological loss of body water that is part of normal postnatal adaptation. This is likely to be of particular relevance to babies with respiratory distress syndrome. A tailored approach to clinical management, delaying the introduction of routine sodium supplements until there has been postnatal loss of body water, is recommended.

(Arch Dis Child Fetal Neonatal Ed 2000;82:F24-F28)

Keywords: sodium and water balance; growth; body composition
Loss of body water is an integral part of the physiology of postnatal adaptation and largely accounts for normal weight loss after birth. ${ }^{1-5}$ In neonates, particularly if preterm, the capacity for sodium excretion is limited. ${ }^{6-8}$ Early sodium supplementation, in excess of excretory capacity, might predispose to delayed loss of body water, with persistent expansion of the extracellular compartment and this in turn might adversely affect outcome, particularly respiratory morbidity.

We conducted a randomised, controlled trial testing the null hypothesis that the timing of sodium supplementation after preterm birth has no effect on outcomes.

\section{Methods}

Infants born between 25 and 30 weeks of gestation, admitted to the neonatal intensive care units at the Hammersmith and Queen Charlotte's Hospitals, London, and requiring respiratory support (either continuous positive airways pressure (CPAP) or positive pressure ventilation) for respiratory distress syndrome, were eligible for entry. Infants with major congenital malformations, chromosomal or renal abnormalities were excluded. The trial was approved by the institutional research ethics committee and informed parental consent was obtained.

Infants were randomly assigned to receive either early or delayed sodium. Randomisation was computer generated, stratified by gender and gestational age. If allocated to the early limb of the trial, the infant was not prescribed sodium for the first 24 hours after birth, and $4 \mathrm{mmol} / \mathrm{kg} /$ day thereafter. Infants in the delayed limb of the trial were prescribed $4 \mathrm{mmol} /$ $\mathrm{kg} /$ day only when $6 \%$ of birthweight had been lost. This choice was based on our previous work showing that $6 \%$ is representative of postnatal weight loss in healthy preterm infants. ${ }^{9}$ Clinical staff caring for the infants were blinded to which limb of the trial the baby was allocated. The appropriate amount of sodium was administered in parenteral nutrition fluid by pharmacy staff. Total fluid volumes were prescribed by attending clinical staff. Hyponatraemia was managed by a reduction in total fluid volume and hypernatraemia by an increase. Glucose flow rate was kept constant by altering the proportions of $5 \%$ and $50 \%$ dextrose infused. ${ }^{10}$ Parenteral energy intakes were not altered. Infants were initially nursed on radiant warmer beds with heat shields until stable, and then transferred to humidified incubators. 
Table 1 Subject details by group

\begin{tabular}{lll}
\hline & Early $(n=24)$ & Delayed $(n=22)$ \\
\hline Male:female & $14: 10$ & $12: 10$ \\
Gestation (weeks/days) & $28(26,30)$ & $27 / 3(25 / 5,30)$ \\
Birthweight $(\mathrm{g})$ & $945(745,1560)$ & $946(420,1570)$ \\
Antenatal steroids & 23 & 22 \\
Antenatal thyrotropin releasing hormone & 12 & 14 \\
Delivery by caesarean section & 16 & 13 \\
CRIB score & $2(1,10)$ & $3.5(0,16)$ \\
Surfactant administration & 21 & 21 \\
Total fluid intake in first week $(\mathrm{ml} / \mathrm{kg})$ & $1084(804,1306)$ & $1087(740,1377)$ \\
Total energy intake in first week $(\mathrm{kcal} / \mathrm{kg})$ & $392(302,579)$ & $461(257,617)$ \\
a:A ratio day 1 & $0.40(0.12,0.72)$ & $0.39(0.10,0.70)$ \\
Ventilation (days) & $3(0,68)$ & $3(0,40)$ \\
\hline
\end{tabular}

Values are counts or median (range). Differences are all non-significant

\section{MEASUREMENTS}

Birthweight, gestational age, surfactant administration and maternal details, including exposure to antenatal steroids were recorded. Infants were weighed daily using scales accurate to \pm 10 g. Weights were recorded until birthweight was regained, or for one week, whichever was the longer period. Total daily fluid, sodium, and energy intakes were calculated from medical and nursing records. Recorded fluid intake included all crystalloid, colloid, drug delivery and flush volumes. True sodium intake was calculated from the sodium concentration and volume of fluid administered. Urine volume and sodium concentration were measured to calculate sodium excretion and sodium balance. Urine was collected by inserting a fine catheter into a urine bag. Urine was aspirated from the bag immediately after voiding. Continuous urine collection is difficult in preterm infants and, therefore, provided urine output from at least 18 hours was available, the amount of sodium excreted in that time period was extrapolated to 24 hours. The results of metabolic monitoring using urine collection of at least 6 hours' duration and with complete 24 hour collections were highly correlated. ${ }^{11}$

\section{BODY WATER COMPARTMENTS}

Total body water (TBW) was measured on days 1,7 , and 14 after birth, and extracellular fluid volume (ECFV) on days 1 and 14, provided that blood samples were taken for clinical reasons on those days. After recruitment TBW was estimated as soon after delivery as was possible. This was within 18 hours of birth in all infants.

TBW measurements were carried out using the Fick principle applied to $\mathrm{H}_{2}{ }^{18} \mathrm{O}$ dilution using a method adapted for neonates. ${ }^{12}$ Briefly, a baseline blood sample was obtained, $1 \mathrm{ml} / \mathrm{kg}$ of water enriched with $\mathrm{H}_{2}{ }^{18} \mathrm{O}$ administered by nasogastric tube, and further blood samples taken at 3 and 6 hours. Exact times of sampling were noted, to extrapolate backwards to a concentration at time zero $\left(\mathrm{C}_{0}\right)$ by linear regression on the $\log _{\mathrm{e}}$ values of ${ }^{18} \mathrm{O}$ concentrations (ppm). Analysis of $\mathrm{H}_{2}{ }^{18} \mathrm{O}$ content was performed using mass spectrometry. ${ }^{13}$

ECFV was measured with TBW determinations on days 1 and 14 after birth using the technique of sodium bromide dilution. ${ }^{14-16}$ Sodium bromide solution $(1 \mathrm{ml} / \mathrm{kg}$ ) containing $100 \mathrm{mg} / \mathrm{ml} \mathrm{NaBr}$ was administered intravenously. Two samples were taken for bromide estimations at 3 to 4 hours and 6 to 8 hours, coinciding with sampling for TBW estimation. Bromide assays were performed using neutron activation analysis at the Imperial College Centre for Analytical Research in the Environment. Concentrations were averaged to provide a single measure for ECFV estimation, which was only obtained on days 1 and 14 after birth because of the long half life of bromide and the possibility of accumulation of bromide to toxic levels. ${ }^{16}$ The calculation of ECFV is based on the method of Bell et $\mathrm{al}^{14}: \mathrm{ECFV}=$ (amount of $\mathrm{BR}$ administered/Serum $[\mathrm{Br}]) \times 0.90 \times 0.95 \times$ 0.934 where 0.90 is the correction factor for intracellular bromide, 0.95 corrects for the Donnan equilibrium across the cell membrane, and 0.934 corrects for the proportion of water in serum. The weight of $\mathrm{NaBr}$ solution administered was measured by weighing the syringe before and after administration of the solution using a chemical balance accurate to $\pm 0.0001 \mathrm{~g}$.

Body solids (BS) were calculated as the difference between body weight and total body water, and intracellular fluid volume (ICFV) as the difference between total and extracellular water compartments.

Data were tested for normality and analysed using parametric or non-parametric tests, as appropriate. All statistical calculations were carried out using Intercooled Stata version 4.0 (Stata Corporation; Texas, USA). Unless otherwise stated, results are presented as median and interquartile range.

\section{Results}

Twenty four infants (14 boys, 10 girls) were recruited to the early and 22 (12 boys, 10 girls) into the delayed limb of the trial. Details of the infants are shown in table 1 .

BODY COMPOSITION (TABLE 2)

There were no significant differences at birth between the two groups in body weight, and in

Table 2 Changes in body composition, days 1, 7, and 14: values are median (interquartile range)

\begin{tabular}{|c|c|c|c|c|c|c|}
\hline & \multicolumn{2}{|l|}{ Day 1} & \multicolumn{2}{|l|}{ Day 7} & \multicolumn{2}{|l|}{ Day 14} \\
\hline & Early & Delayed & Early & Delayed & Early & Delayed \\
\hline Weight (g) & $945(870,1120)$ & $946(740,1110)$ & $820 \Omega(800,980)$ & $795 \rrbracket(670,1010)$ & $960+(920,1150)$ & $930+(800,1130)$ \\
\hline TBW (ml/kg) & $864(822,900)$ & $835(809,880)$ & $848 \ddagger(824,913)$ & $791^{\star} \ddagger(764,833)$ & $872(792,944)$ & $820(794,829)$ \\
\hline ECFV (ml/kg) & $513(461,531)$ & $501(455,527)$ & & & $451(423,489)$ & $433^{\star \star}(420,489)$ \\
\hline $\mathrm{ICFV}(\mathrm{ml} / \mathrm{kg})$ & $362(320,406)$ & $349(282,384)$ & & & $415(367,484)$ & $385(325,414)$ \\
\hline $\mathrm{BS}(\mathrm{g} / \mathrm{kg})$ & $136(100,178)$ & $170(122,191)$ & $157 \ddagger(118,176)$ & $209 \ddagger(167,236)$ & $151(86,217)$ & $180(171,206)$ \\
\hline
\end{tabular}

Swithin group change from day $1(\mathrm{p}<0.001)$

twithin group change from day $7(\mathrm{p}<0.001)$

${ }^{\star}$ within group change, significant difference from day $1(p=0.048)$

$\star \star$ within group change, significant difference from day $1(p=0.01)$

$\ddagger$ significant between group difference $(\mathrm{p}=0.013)$ 

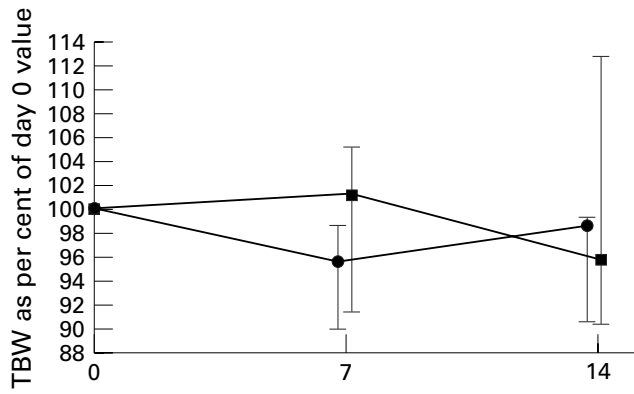
Figure 1 Total body water as a percentage of value at broup.

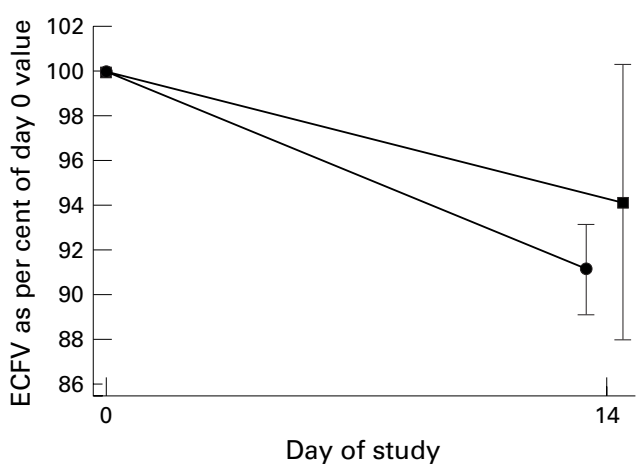

Figure 2 Extracellular fluid volume as a percentage of value at birth: squares denote early group; circles denote delayed group.

the proportion of body weight represented by ECFV, TBW, ICFV and BS. During the first week the delayed group, but not the early group, lost TBW (delayed $-44 \mathrm{ml} / \mathrm{kg}(-94$, -11) $\mathrm{p}=0.048$; early, $6 \mathrm{ml} / \mathrm{kg} \quad(-75,44)$ $\mathrm{p}=0.970$ ) (fig 1 ). In addition, the delayed group, but not the early group, showed a significant loss of ECFV over the two weeks after birth (delayed, $-53 \mathrm{ml} / \mathrm{kg}(-72,-27)$ $\mathrm{p}=0.01$; early $-37 \mathrm{ml} / \mathrm{kg}(-93,1) \mathrm{p}=0.2)$ (fig 2$)$.

There was no significant difference in absolute change in BS (delayed $12 \mathrm{~g}(-25,67)$; early $-8 \mathrm{~g}(-44,59) \mathrm{p}=0.3)$. However, the difference in loss of body water resulted in a significant difference in body composition by

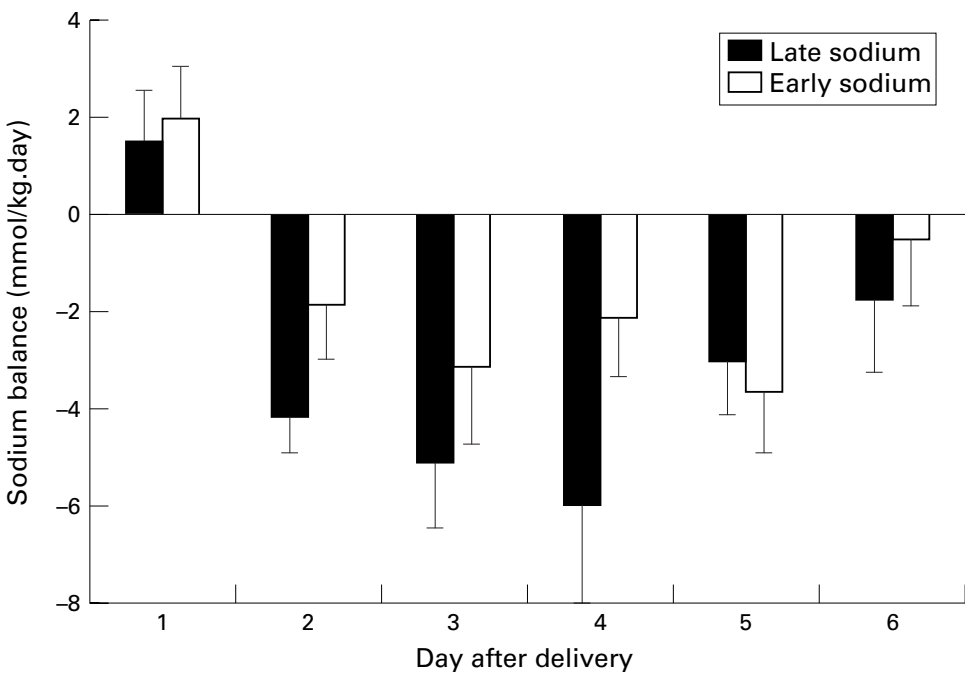

Figure 3 Daily sodium balance (mmol/kg/day). Values are mean (SE). day 7 (TBW, delayed $791 \mathrm{ml} / \mathrm{kg}$ (764, 833), early $848 \mathrm{ml} / \mathrm{kg}(824,913), \mathrm{p}=0.013)$.

By day 14, the BS content of the early sodium group had increased by a median of $51 \%$ over the absolute BS content at birth $(-35 \%, 82 \%, \mathrm{p}=0.06)$ and the late group by $5 \%(-3 \%, 64 \%, p=0.17)$. Intracellular fluid volume in the early group changed by a median of $20 \%(-1 \%, 41 \%, \mathrm{p}=0.10)$ and in the delayed group by $-4 \%(-37 \%, 52 \%, \mathrm{p}=0.87)$.

By day 14 there were once again no significant differences in body composition and body water compartments between the two groups.

SODIUM BALANCE

Sodium balance was positive in both groups on the first day after birth but negative thereafter (fig 3). There was no difference in sodium intake on the first day but a significant difference on subsequent days up to the time of $6 \%$ weight loss (median sodium intake $(\mathrm{mmol} /$ $\mathrm{kg}$ /day), early 3.93; delayed $1.07 ; \mathrm{p}=0.0001$ ). Although sodium was not formally prescribed in the first 24 hours after birth, both groups received a substantial intake (median sodium intake (mmol/kg/day), early 3.8; delayed 3.7) from colloid, blood products, medications and flush fluids. The fractional excretion of sodium of the two groups did not differ on any of the days measured.

\section{Discussion}

Loss of body water after birth has been shown before, ${ }^{1-5}{ }^{9}$ but few studies have examined the effect on body composition of different regimens of sodium supplementation. Although it is common practice to prescribe a sodium intake of $4-6 \mathrm{mmol} / \mathrm{kg} /$ day for preterm infants in intensive care, from the second day after birth ${ }^{17}$ there are grounds for suggesting that a more tailored approach might be advantageous.

Loss of body water after birth seems to be a prerequisite for successful postnatal adaptation. Most published studies report a decline in TBW after birth although van der Wagen et all and Bauer et $a l^{19}$ found no loss in babies who were small for gestational age. Cheek et al ${ }^{20}$ found that TBW in full term infants remained constant over the first 14 days after delivery, but that TBW in preterm infants fell between days 7 and 14, having been constant up to that point. In contrast to other reports, these data were derived from cross sectional, rather than longitudinal, observations.

Postnatal loss of TBW seems to derive principally from the extracellular compartment. ${ }^{1-5} 2021$ Singhi et $a l^{5}$ studied babies between 31-36 weeks of gestation, and showed a weight loss due to a decrease in TBW, of which $90 \%$ was accounted for by a loss of ECW. Bauer et al ${ }^{4}$ also demonstrated a significant correlation between the decrease in TBW and ECFV at the time of maximum weight loss in babies from 26 to 30 weeks. In none of these studies was sodium intake specified.

Although healthy term infants and some healthy preterm infants can handle a modest sodium load, ${ }^{2}$ preterm infants have a limited 
capacity for sodium excretion, ${ }^{6-8}$ although this matures with postnatal age. ${ }^{22} 24$ In healthy newborn babies, despite the requirement for sodium retention to support growth, an increase in sodium intake immediately after birth leads to an increase in excretion until body water compartments contract. ${ }^{25}$ If excretory capacity is exceeded, persistent expansion of the extracellular compartment would result. To our knowledge, only two studies have already addressed this possibility.

Shaffer and $\mathrm{Meade}^{2}$ randomised 20 preterm infants ranging in gestation from 25-31 weeks to receive either 1 or $3 \mathrm{mmol}$ sodium $/ \mathrm{kg} /$ day for the first 10 days after birth. There were no differences between the groups in ECFV measured on days 1, 5, 10, 20 and 30. Both groups showed a decline up to day 10 after which ECFV remained constant. They concluded that these infants were able to compensate for moderate differences in early sodium intake. In this study, however, babies with severe respiratory disease were specifically excluded. Costarino et $a l^{6}$ randomised 17 preterm infants to receive either no sodium or 3-4 mmol/kg/day. Body water compartments were not measured, nor were the infants' weights reported, but sodium balance was initially positive in the group receiving the higher intake. In our study sodium intake was positive in both groups on the first day after birth when both groups received a substantial "inadvertent" sodium intake (early 3.8; delayed 3.7 $\mathrm{mmol} / \mathrm{kg} /$ day), derived from medications, flush fluids, and volume support fluids. Intakes of unprescribed sodium are inevitably greater the more unwell the infant. Furthermore, infants with respiratory distress syndrome are particularly vulnerable to an excessive sodium intake as the time of onset of loss of extracellular fluid is related to cardiopulmonary adaptation, only occurring with improvement in respiratory function. ${ }^{26-28}$

There is also another concern which merits consideration-namely, that delay in achieving an adequate sodium intake might compromise postnatal growth. The amount of intracellular water may be taken as a measure of cell mass, with increasing intracellular water content taken to indicate cell growth, either through enlargement of existing cells or through cell division. In this study both groups received a similar energy intake but ICFV in the early group showed a trend to increase from days 1 to 14 , whereas that of the late supplemented group showed no significant change.

Comparison with other published work is hindered by the fact that nutritional intakes varied widely. Van der Wagen et al ${ }^{18}$ showed an initial loss of BS in SGA infants up to the time of maximal weight loss, followed by an increase in BS to the time of regaining birthweight, and concluded that these changes in body composition were due to initial catabolism followed by growth. Bauer et $a l^{4}$ investigated AGA preterm infants and found no changes in BS over the period from birth to maximum weight loss up to regaining birth weight. However, in a later study, Bauer et $a l^{19}$ compared AGA and SGA babies, and found that BS did not change in either group over the first six days after delivery, but increased significantly from days 6 to 23 in AGA but not in SGA babies, a difference they were unable to explain. Heimler et $a l^{11}$ measured body composition on days 1 and day 7 after delivery in 14 preterm infants with a mean gestational age of 30.7 weeks. In the group as a whole they showed an increase in ICFV of $8.5 \%$ over the 7 days. In infants who lost $>10 \%$ of birthweight there was no change in ICFV, but in those who lost $<5 \%$ of birthweight there was a significant increase in ICFV. They also noted that infants in whom weight loss was greater were more unstable and had a significantly lower energy intake. They concluded that with an adequate energy intake, weight loss is minimised because of an expansion in ICFV, and speculated that this was indicative of the onset of growth.

In a study of 23 healthy AGA preterm infants, Singhi et at showed a gradual increase in BS up to the time of regaining birthweight, associated with a fall in TBW and ECFV and an increase in ICFV, indicating what would seem to be normal postnatal adaptation with immediate onset of growth from birth. Similarly, previous work from our group has shown that an absolute gain in body solid content accompanies postnatal weight loss if energy intake is sufficient ${ }^{9}$ : in other words growth accompanies postnatal water loss. In our study, the within group analyses of absolute body solid content showed no change in the late group, but a trend towards an increase in the early group, consistent with the trend to increase in ICFV. There was no difference in energy intake between the groups. Further investigation of the possibility that sodium supplementation in the early group acted as a growth promoter is warranted.

We have shown that a small alteration in the timing of routine sodium supplements in preterm infants has measurable and significant effects on body composition by one week after birth. Normal loss of body water from the extracellular compartment is impaired. Persistent expansion of body water content after birth has been shown to be associated with greater respiratory morbidity ${ }^{27}$ and we suggest that optimal care in preterm infants is for clinical management to be tailored to the pace of postnatal adaptation. Routine sodium supplements should be withheld until there is postnatal loss of body water, marked clinically by weight loss.

PB was supported by a European Union Human Capital and Mobility Grant. We gratefully acknowledge the assistance of Ms Caroline Dore, Medical Statistics Unit, Hammersmith Hospital, Ms Beryl Langfield, Pharmacy, Hammersmith Hospital, and Dr Roger Benzing and Dr Susan Parry, Imperial College Centre for Analytical Research in the Environment.

1 Shaffer SG, Bradt SK, Hall RT. Postnatal changes in total body water and extracellular volume in the preterm infant with respiratory distress syndrome. 7 Pediatr 1986;109:509-14

2 Shaffer SG, Meade VM. Sodium balance and extracellular volume regulation in very low birth weight infants. $\mathcal{F}$ Pediatr 1989;115:285-90.

3 Bauer K, Versmold H. Postnatal weight loss in preterm neonates less than $1,500 \mathrm{~g}$ is due to isotonic dehydration of the extracellular volume. Acta Paediatr Scand 1989;360:37-42. 
4 Bauer K, Bovermann G, Roithmaier A, Gotz M, Proiss A, Versmold HT. Body composition, nutrition, and fluid balance during the first two weeks of life in preterm neonates weighing less than 1500 grams. F Pediatr 1991;118:61520.

5 Singhi S, Sood V, Bhakoo ON, Ganguly NK, Kaur A. Composition of postnatal weight loss \& subsequent weight gain in preterm infants. Indian $\mathcal{F}$ Med Res 1995;101:157-62.

6 Costarino AT, Gruskay JA, Corcoran L, Polin RA Baumgart S. Sodium restriction versus daily maintenance replacement in very low birth weight premature neonates: a randomized,

7 Robillard JE, Smith FG, Segar JL, Guillery EN, Jose PA. Mechanisms regulating renal sodium excretion during development. Pediatr Nephrol 1992;6:205-13.

8 Spitzer A. The role of the kidney in sodium homeostasis during maturation. Kidney Int 1982;21:539-45.

9 Tang W, Ridout D, and Modi N. Influence of respiratory distress syndrome on body composition after preterm distress syndrome on body composition after preterm

10 Al-Rubeyi B, Murray N, Modi N.A variable dextrose delivery system for use in neonatal intensive care. Arch Dis 1994:70:F79

11 Boehm G, Wiener M, Schmidt C, Ungethum B, Moro G Usefulness of short term urine collection in the nutritional monitoring of low birthweight infants. Acta Paediatr 1998; 87:339-43.

12 Tang W, Modi N, Clark P. Dilution kinetics of $\mathrm{H}_{2}{ }^{18} \mathrm{O}$ for the measurement of total body water in preterm babies in the first week after birth. Arch Dis Child 1993;69:28-31.

13 Prosser SJ, Brookes ST, Linton A, Preston T. Rapid, automated analysis of $13 \mathrm{C}$ and $18 \mathrm{O}$ of $\mathrm{CO} 2$ in gas samples by continuous-flow, isotope ratio mass spectrometry. Biological Mass Spectrometry 1991;20:724-30.

14 Bell EF, Ziegler EE, Forbes GB. Corrected bromide space. Pediatr Res 1984;18:392-3.

15 Shaffer SG, Ekblad H, Brans YW. Estimation of extracellular fluid volume by bromide dilution in infants less than lar fluid volume by bromide dilution in infants less than

16 Tang, W. The validation of bioelectrical impedance analysis to measure body water distribution in preterm neonates. [Thesis]. University of Sheffield: 1996
17 Speidel B, Fleming PJ, Henderson J, et al, eds. Fluid and lectrolyte therapy In: A Nematal Vade Mecum. 3rd edn. electrolyte therapy. In: A Neonatal Vade

18 Van der Wagen A, Okken A, Zweens J, Zijlstra WG. Composition of postnatal weight loss and subsequent weight gain in small for dates newborn infants. Acta Paediatr Scand 1985;74:57-61

19 Bauer K, Cowett RM, Howard GM, van Epp J, Oh W. Effect of intrauterine growth retardation on postnatal weight change in preterm infants. $\mathcal{F}$ Pediatr 1993;123:301-6.

20 Cheek DB, Wishart J, MacLennan AH, Haslam R. Cell hydration in the normally grown, the premature and the low weight for gestational age infant. Early Hum Dev 1984;10:75-84.

21 Heimler R, Doumas BT, Jendrzejczak BM, Nemeth PB, Hoffman RG, Nelin LD. Relationship between nutrition, weight change, and fluid compartments in preterm infants during the first week of life. Fediatr 1993;122:110-4.

22 Midgley J, Modi N, Littleton P, Carter N, Royston P, Smith A. Atrial natriuretic peptide, cyclic guanosine monophosphate and sodium excretion during postnatal adaptation in male infants below 34 weeks gestation with severe respiratory distress syndrome. Early Hum Dev 1992;28:145-54.

23 Al-Dahan J, Haycock GB, Chantler C, Stimmler L. Sodium homeostasis in term and preterm neonates. I. Renal aspects. Arch Dis Child.1983;58:335-42.

24 Sulyok E, Varga F, Gyory E, Jobst K, Csaba IF. Postnatal development of renal sodium handling in premature infants. F Pediatr 1979;95:787-92.

25 Rees L, Shaw JC, Brook CG, Forsling ML. Hyponatraemia in the first week of life in preterm infants. Part II. Sodium and water balance. Arch Dis Child 1984;59:423-9.

26 Langman CB, Engle WD, Baumgart S, Fox WW, Polin RA. The diuretic phase of respiratory distress syndrome and its relationship to oxygenation. $\mathcal{F}$ Pediatr 1981;98:462-6.

27 Spitzer AR, Fox WW, Delivoria-Papadopoulos M. Maximum diuresis-a factor in predicting recovery from respiratory distress syndrome and the development of bronchopulmonary dysplasia. F Pediatr 1981;98:476-9.

28 Green TP, Thompson TR, Johnson DE, Lock JE. Diuresis and pulmonary function in premature infants with respiratory distress syndrome. $\mathcal{F}$ Pediatr 1983;103:618-23. 